\title{
AVALIAÇÃO DA ESTABILIDADE DE CONTROLES PARA ANÁLISES DE DIAGNÓSTICO IN VITRO EM CONDIÇÕES DE TEMPERATURA REAIS DE TRABALHO LABORATORIAL
}

\author{
EVALUATION OF THE STABILITY OF CONTROL FOR IN VITRO \\ DIAGNOSTIC ANALYZES UNDER REAL LABOR LABORATORY \\ TEMPERATURE CONDITIONS
}

Marineuza Paiva Albarado ${ }^{1^{*}}$, Geovani Waghan Figueira ${ }^{2}$, Kaio Vinícius Paiva Albarado ${ }^{3}$, Paula Luane Cruz da Silva ${ }^{1}$, Jamille Gomes dos Santos Saatkamp ${ }^{4}$, Mauricio Liberal de Almeida 1 .

${ }^{1}$ Centro Universitário da Amazônia, Santarém, PA, Brasil.

${ }^{2}$ Instituto Esperança de Ensino Superior, Santarém, PA, Brasil.

${ }^{3}$ Universidade Federal do Oeste do Pará, Itaituba, PA, Brasil.

${ }^{4}$ Universidade Paulista-UNIP, Santos, SP, Brasil.

*marialbarado@yahoo.com.br

Recebido em: 14/05/2019; Aceito em: 06/10/2020.

\section{RESUMO}

A garantia da qualidade é o mecanismo que propicia ao laboratório de análises clínicas apresentar resultados confiáveis adequados e corretamente interpretados. Na rotina de trabalho desses laboratórios, utilizam-se calibradores, que são padrões conhecidos com características quantitativas e/ou qualitativas determinadas, os controles podem ser utilizados para medir alguns parâmetros de qualidade laboratorial. A depender dos fabricantes, existem algumas sugestões de manuseio a ser seguido, para então, obter maior fidedignidade de aferição. O desempenho do calibrador pode ser afetado por erros de reconstituição, de homogeneização, armazenamento incorreto, contaminação da água ou vidraria. Dessa forma, este trabalho avaliou a estabilidade de controles comerciais submetidos a temperaturas diversas encontradas em situações reais de laboratório, como a refrigeração entre 4-8 ${ }^{\circ} \mathrm{C}$, exposição sob bancada de trabalho, a temperatura ambiente, e armazenada dentro de um automóvel, em temperaturas de 60-80 ํㅡ, por períodos de 1 a 12 dias. Tanto o tempo quanto a temperatura em que as alíquotas são armazenadas não ocasionaram alterações nesse produto (exceto para a creatinina, apresentou-se instável no $12^{\circ}$ dia do estudo), apresentando valores dentro das faixas estimadas, e possivelmente as alíquotas fora das faixas estimadas devem-se a erro sistemático.

Palavras-chave: Controle. Controle de Qualidade. Diagnóstico in vitro.

\section{ABSTRACT}

Quality assurance is the tool that enables the clinical analysis laboratory to provide reliable, appropriately and correctly interpreted results. Calibrators are used in the routine of these laboratories, which are known standards with de- 
terminated quantitative and / or qualitative characteristics used to calibrate, calibrate, or adjust a measurement procedure. Control are used for multiparameter calibration at the same time and should be used in accordance with manufacturer's recommendations. Calibrator performance may be affected by reconstitution, homogenization, improper storage, water contamination, or glassmaking errors. Thus, this work evaluated the stability of commercial control submitted to different temperatures in real laboratory situations, such as refrigeration between 4-8 ${ }^{\circ} \mathrm{C}$, exposure under a working bench, at room temperature, and stored inside a car, at temperatures of $60-80{ }^{\circ} \mathrm{C}$, for periods of 1 to 12 days. Both the time and the temperature at which the aliquots are stored did not cause changes in this product (except for creatinine, which was unstable on the 12th day of the study), presenting values within the estimated ranges, and possibly the aliquots outside the estimated ranges follow a systematic error.

Keywords: Control. In vitro diagnosis. Quality Control.

\section{INTRODUÇÃO}

Os sistemas de qualidade em laboratórios de análises clínicas estão evoluindo devido as necessidades de melhoria de qualidade, fazendo com que tais instituições aprimorem seus sistemas de controle. Considerando-se o desenvolvimento da tecnologia, as exigências de qualidade dos usuários, além do grande número de análises realizadas e os possíveis problemas judiciais em casos de erros, cresce a necessidade dos laboratórios de cuidar da geração de informações tanto quanto da qualidade de seus serviços. A garantia da qualidade é o mecanismo que propicia o laboratório apresentar resultados confiáveis adequados e corretamente interpretados. Então, para que se tenha maior acurácia nos resultados, todos os testes possuem a garantia de qualidade necessária. Nesse caso, todos os testes laboratoriais, para fins de confiança, devem possuir os critérios próprios para alcançar a qualidade desejada do produto (WESTGARD; KLEE, 2006; TAMBWEKAR, 2009).

$O$ processo de controle de qualidade, se dá pelo erro analítico. Este, possui um conjunto de normas de fiscalização a partir das amostras coletadas. No entanto, o sistema analítico compreende desde a funcionamento dos reagentes, instrumentação dos testes até se chegar as amostras dos pacientes e amostras-controle (BROOKS, 2001; BADRICK, 2008).

O calibrador tem a importância de obter o melhor resultado em uma análise, ele é utilizado para equiparar resposta já concluídas com as que ainda serão feitas. Existe alguns tipos de calibradores, que são os primários e os secundários, mas os que se aproximam mais das amostras humanas são os padrões secundário (RICÓS et al., 1999; WESTGARD; KLEE, 2006).

Além disso, os padrões secundários por serem similar as amostras humanas, são os mais utilizados. Com tudo, os calibradores podem ser específicos quando direcionados somente para um padrão ou medida, verificando sempre as sugestões dos fabricantes (KA; NAMIESNIK, 2009; TAMBWEKAR, 2009).

Calibradores proteicos são padrões secundários que surgiram no mercado para serem usados em equipamentos automáticos, uma vez que os 
padrões aquosos não eram adequados. Estes são produzidos em uma matriz proteica e os analitos são determinados através de métodos de referência calibrados com padrões primários. Por terem a matriz proteica, geralmente humana, e apresentarem viscosidade semelhante as amostras humanas, os calibradores são bem adequados para uso em sistemas automáticos (LOPES, 2013).

Segundo as instruções apresentadas dos controles de diversas empresas, o produto é estável até o vencimento da data de validade impressa no rótulo do produto e na caixa quando conservado na temperatura recomendada, bem vedado e for evitada a contaminação durante o uso. $O$ desempenho do calibrador pode ser afetado por vários fatores como: erros de reconstituição, de homogeneização, armazenamento incorreto, contaminação da água ou vidraria (LOPES, 2013).

Sabe-se, porém, que no dia-a-dia das rotinas de trabalho, podem ocorrer erros devido a ações humanas inadequadas em relação as práticas de laboratório, como por exemplo o armazenamento inadequado dos calibradores, em temperaturas acima daquelas recomendadas, ou mesmo a exposição durante 0 uso, por determinado tempo, a temperaturas fora daquelas estabelecidas pelo fabricante. Sabendo-se da estabilidade desses reagentes, sabe-se que tais podem sofrer degradação ou alteração devido a esta exposição a temperaturas inadequadas, ocasionando assim erros nas análises in vitro. Dessa forma, este trabalho avaliou a estabilidade de controles comerciais submetidos a temperaturas diversas encontradas em situações reais de laboratório.

\section{MATERIAL E MÉTODOS}

Para avaliação da influência das temperaturas de armazenamento na efetividade dos controles, os experimentos foram realizados em março de 2019, onde foi utilizado o controle Qualitrol $1 \mathrm{H}$ da marca Labtest, lote 1802, com expiração em 04/08/2021. O procedimento para preparo das alíquotas foi feito como a bula do controle Qualitrol 1H determina. Golpeou-se o frasco levemente com os dedos para desprender o material liofilizado. Removeu-se as tampas de plástico e borracha. Utilizando uma pipeta volumétrica, adicionou-se ao frasco $5,0 \mathrm{ml}$ de água destilada, a temperatura de $22-28^{\circ} \mathrm{C}$. Recolocou-se a tampa de borracha. Golpeou-se o frasco suavemente com os dedos. Deixou-se em repouso durante 10 minutos e homogeneizou-se suavemente por rotação para misturar o conteúdo. Intermitentemente durante os próximos 10 minutos, inverteu-se o frasco suavemente até dissolução completamente do material.

Depois do preparo das alíquotas, foram feitas as distribuições aos locais de exposição. Seis foram armazenadas na geladeira de 2 a $8{ }^{\circ} \mathrm{C}$ e a média fica em torno de $5,5^{\circ} \mathrm{C}$, outras seis ficaram armazenadas na bancada de 20 a $25^{\circ} \mathrm{C}$ e a média fica em torno de $23,5^{\circ} \mathrm{C}$, outras seis foram alocadas dentro do carro com temperatura entre 60 e $80^{\circ} \mathrm{C}$ e a média fica em torno de $70{ }^{\circ} \mathrm{C}$. Todas as alíquotas com temperaturas variadas foram submetidas diariamente durante 5 dias consecutivos, e no $12^{\circ}$ dia após o preparo, a avaliação das concentrações de glicose, colesterol, ureia, creatinina, triglicéride, transaminase oxalacética (TGO ou AST) e transaminase pirúvica (TGP ou ALT). Esses testes foram feitos 
utilizando-se de um equipamento de bioquímica BS - 200E - Mindray, utilizandose $240 \mu \mathrm{L}$ das alíquotas em cubetas apropriadas do equipamento. Os valores médios e a faixa de concentração dos constituintes do controle testado após 0 adequado preparo seguem na Tabela 1.

Tabela 1 - Valores médios e faixa de concentração dos analitos avaliados no controle testado

\begin{tabular}{lccc}
\hline Analito & Valor médio no controle & Intervalo & Unidade \\
\hline Glicose & 91 & $77-105$ & $\mathrm{mg} / \mathrm{dL}$ \\
Colesterol & 81 & $69-93$ & $\mathrm{mg} / \mathrm{dL}$ \\
Triglicérides & 115 & $98-132$ & $\mathrm{mg} / \mathrm{dL}$ \\
Uréia & 34 & $29-39$ & $\mathrm{mg} / \mathrm{dL}$ \\
Creatinina & 1,10 & $0,94-1,27$ & $\mathrm{mg} / \mathrm{DI}$ \\
TGO & 45 & $36-54$ & $\mathrm{U} / \mathrm{L}$ \\
TGP & 43 & $34-52$ & $\mathrm{U} / \mathrm{L}$ \\
\hline
\end{tabular}

Fonte: os autores.

De acordo com as instruções de uso, durante o manuseio, o produto está sujeito a contaminações de natureza química e microbiana que podem provocar redução da estabilidade. Após reconstituição, os constituintes do Qualitrol $1 \mathrm{H}$, exceto os triglicérides, são estáveis durante 7 dias entre $2-8{ }^{\circ} \mathrm{C}$ em frasco bem vedado protegido da ação da luz. Os triglicérides são estáveis por 3 dias entre $2-8^{\circ} \mathrm{C}$ em frasco bem vedado. Todos os constituintes avaliados são estáveis por 15 dias quando armazenados a $20^{\circ} \mathrm{C}$ negativos, em recipiente hermeticamente fechado e protegido da luz.

\section{RESULTADOS E DISCUSSÃO}

Os resultados a seguir, são referentes as análises da concentração dos analitos glicose (Figura 1), colesterol (Figura 2), triglicérides (Figura 3), ureia (Figura 4), creatinina (Figura 5), TGO (Figura 6) e TGP (Figura 7).

Para a glicose (Figura 1), até $5^{0}$ dia de experimento, as alíquotas submetidas as três temperaturas de armazenamento, apresentaram valores dentro da faixa de concentração estabelecida nas informações do controle. Já nas alíquotas armazenadas na bancada, à temperatura ambiente (aproximadamente $28^{\circ} \mathrm{C}$ ) e sob refrigeração $\left({ }^{\circ}{ }^{\circ} \mathrm{C}\right.$ ), as alíquotas permaneceram dentro dos limites estabelecidos.

Entretanto, para a alíquota armazenada na temperatura mais alta (no carro, com temperaturas entre 60 a $80^{\circ} \mathrm{C}$ ), houve concentração acima do estabelecido nas instruções de uso mensurada no $12^{\circ}$ dia.

Pode-se supor que a exposição das alíquotas a temperaturas acima daquela recomendada, ocasionam evaporação da água utilizada na reconstituição, levando a valores de concentração acima dos estabelecidos nas instruções de uso. $\mathrm{O}$ armazenamento a $4 \stackrel{\circ}{\circ}$, na geladeira, e em temperatura ambiente mantiveram as concentrações de glicose dentro da faixa estabelecida para o produto. 
Figura 1 - Valores obtidos para o analito glicose após o armazenamento em diferentes temperaturas.

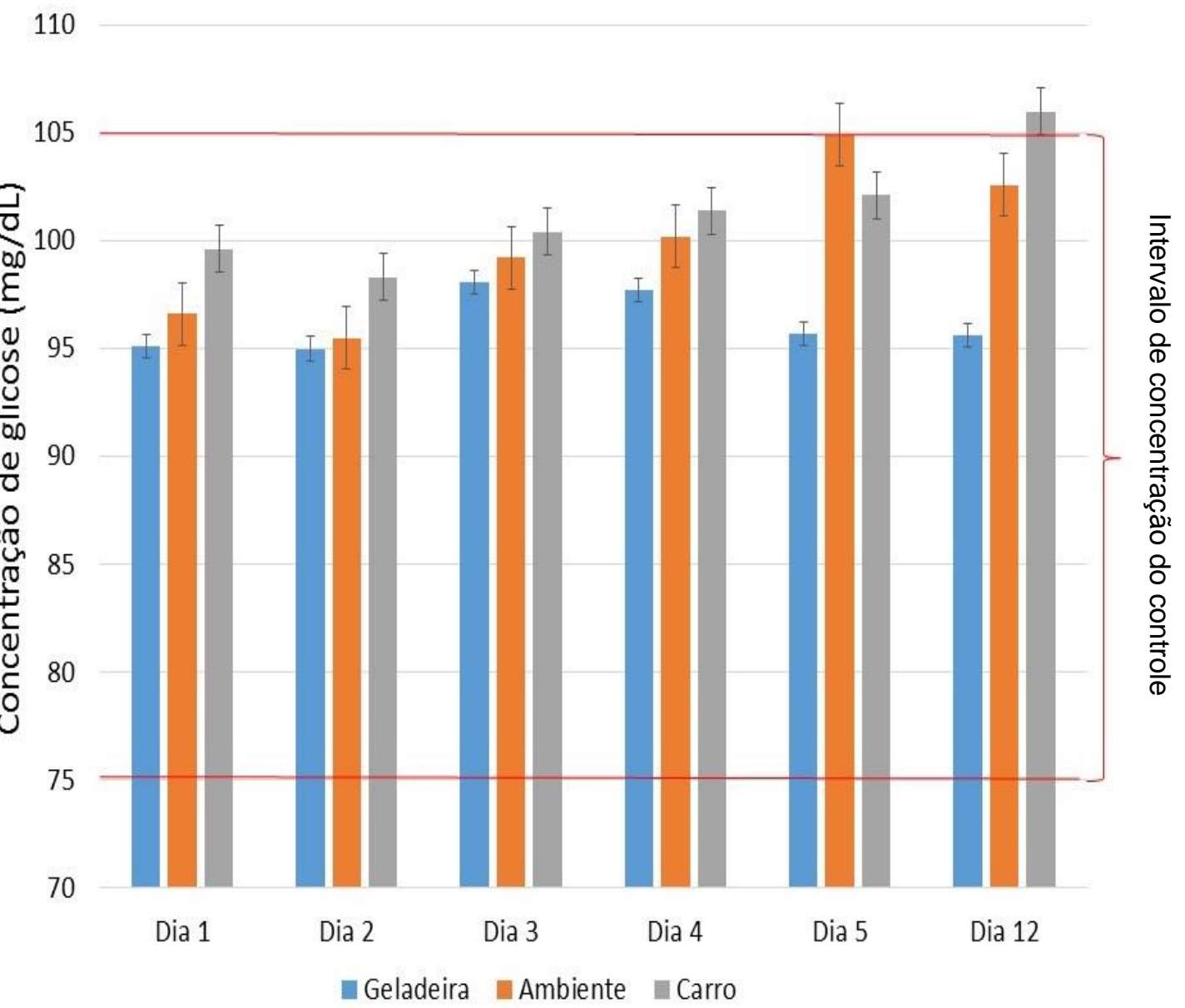

Fonte: os autores.

Para o analito colesterol (Figura 2), com exceção das alíquotas armazenadas a temperatura ambiente no $2^{\circ}$ e $3^{\circ}$ dia, todas as demais apresentaram concentração dentro dos limites estabelecidos nas instruções de uso do produto. Em estudos de Rosato (2007) foi verificado que sob armazenamento a $25^{\circ} \mathrm{C}$, a concentração de colesterol em amostras de soro de cães foi instável a partir de $7^{\circ}$ dia. Segundo resultados dos estudos de lange et al. (1995), o colesterol apresenta variações na concentração em plasma canino armazenados a -20 e $-70{ }^{\circ} \mathrm{C}$, devido a temperatura e ao tempo de armazenamento. Porém, apesar da possibilidade da instabilidade do colesterol, observa-se que os valores acima dos limites são presentes apenas nas alíquotas armazenadas a temperatura ambiente no $2^{\circ}$ e $3^{\circ}$ dia, enquanto no $1^{\circ}$ dia e do $4^{\circ}$ dia em diante, as concentrações observadas estavam dentro da faixa estabelecida pelo fabricante. Como estes dados não demonstram evidências de degradação das amostras com uma linha de tendência consistente de aumento ou diminuição dos resultados ao longo do tempo, pode-se supor então erro sistemático como causa da variabilidade observada (LANGE et al., 2018). 
Figura 2 - Valores obtidos para o analito colesterol após o armazenamento em diferentes temperaturas

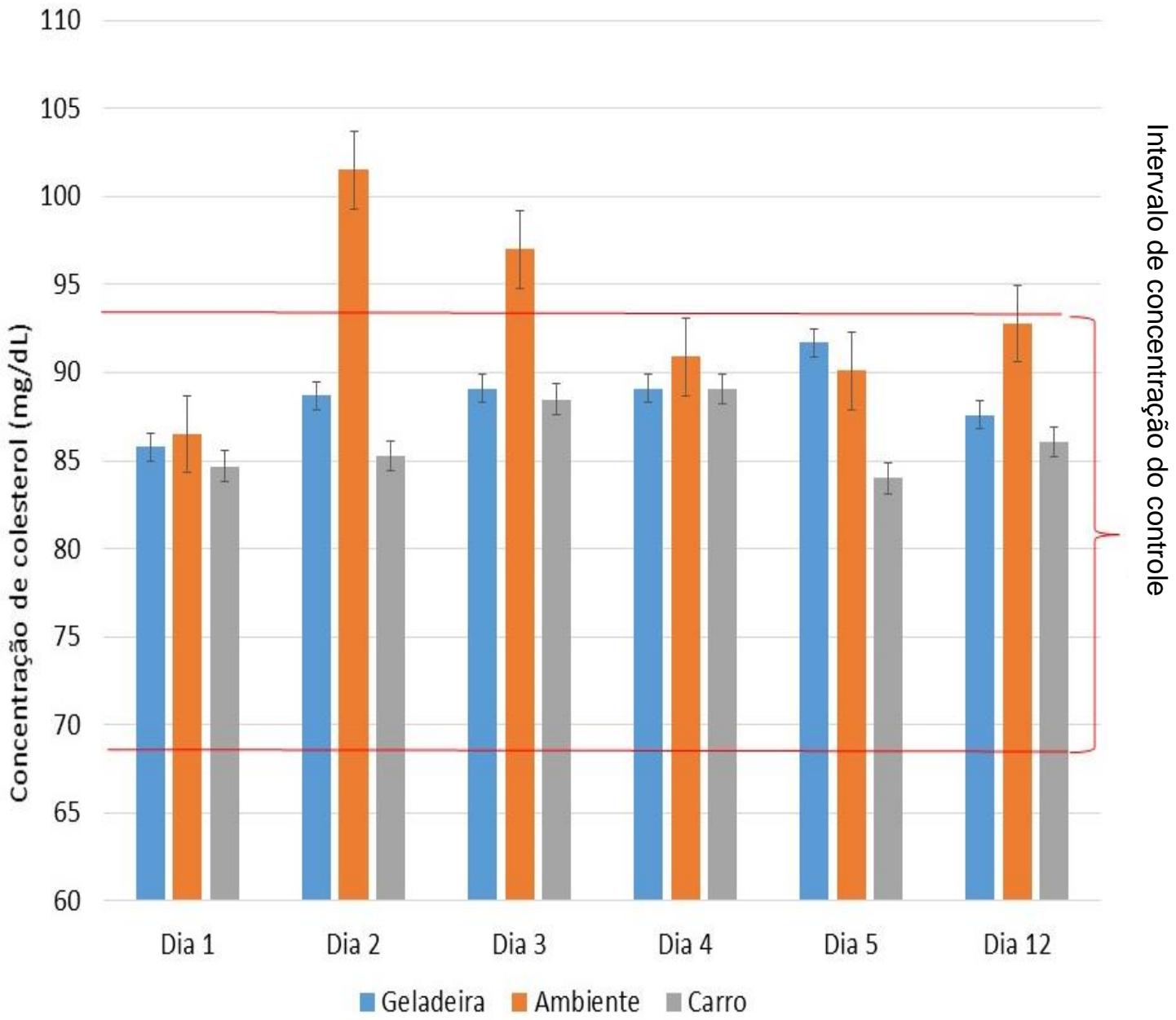

Fonte: os autores

Em relação ao analito triglicérides (Figura 3), todas as temperaturas de armazenagem, em todos os dias analisados, a concentração mensurada esteve dentro da faixa descrita para tal analito no controle, com exceção da alíquota armazenada em temperatura ambiente no $3^{\circ}$ dia.

Corroborando a isso, Rosato (2007) observou aumento da concentração de triglicérides em soro de cães a partir de 24 horas sob armazenagem a 4 e 25 -C. Resultados compatíveis com os dados desta pesquisa, foram verificados por Heins et al. (1995) onde evidenciaram aumento da concentração de triglicérides em amostras de soro humano armazenadas em temperatura ambiente, com os valores mensurados aumentando continuamente com 0 tempo de armazenagem.

Observa-se, porém que esta mesma amostra se apresentou fora da faixa de concentração descrita para o colesterol, o que dá indícios da ocorrência de erro sistemático, visto que a concentração de triglicérides não apresenta tendência de aumento com o tempo. 
Figura 3 - Valores obtidos para o analito triglicérides após o armazenamento em diferentes temperaturas

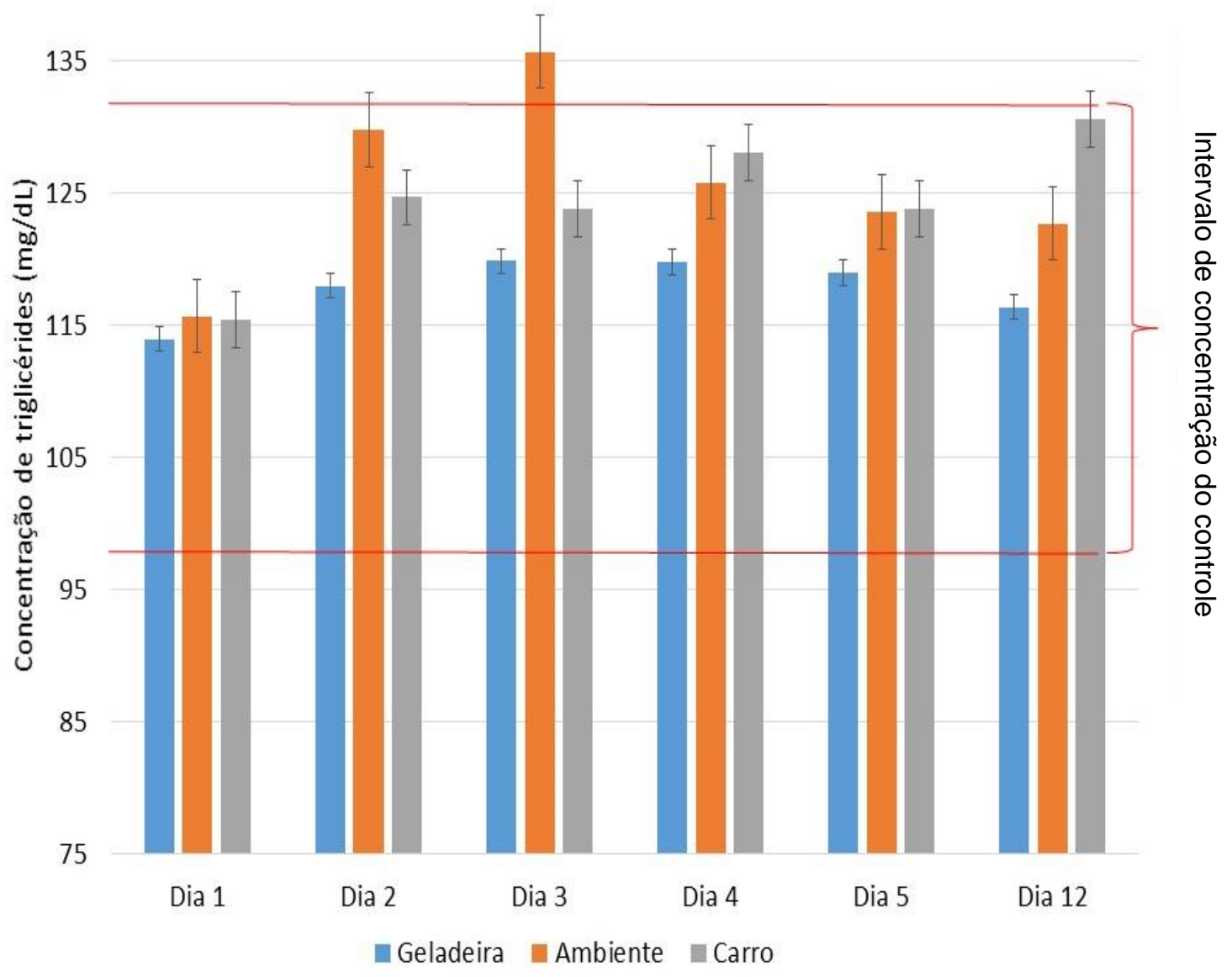

Fonte: os autores.

Para o analito ureia (Figura 4), observa-se que as todas as alíquotas apresentaram valores dentro da faixa estabelecida nas instruções de uso do controle. Rosato (2007) reporta que os dados obtidos de concentração de ureia sérica em soro de cães apresentaram instabilidade em amostras mantidas a temperatura ambiente com 8 horas de armazenagem. Thoresen et al. (1995) reportaram variação da concentração de ureia em soro canino com o tempo de armazenamento, mas não houve variação devido a temperatura as quais as amostras foram submetidas. Lindner (1991) relatou instabilidade da ureia em amostras de sangue de equinos em temperaturas ambiente e de refrigeração. Fernandes et al. (2001) observaram que a ureia plasmática de cães apresentou alterações significativas (diminuição da concentração) a $6 \mathrm{~h}$ e $72 \mathrm{~h}$ após a primeira análise, quando submetidas à armazenamento em temperatura ambiente e refrigeração entre 2 e $8 \stackrel{\circ}{ } \mathrm{C}$, respectivamente. Observa-se assim que diferentemente de amostras reais, o controle avaliado manteve a estabilidade da ureia nas condições estudadas. 
Figura 4 - Valores obtidos para o analito ureia após o armazenamento em diferentes temperaturas

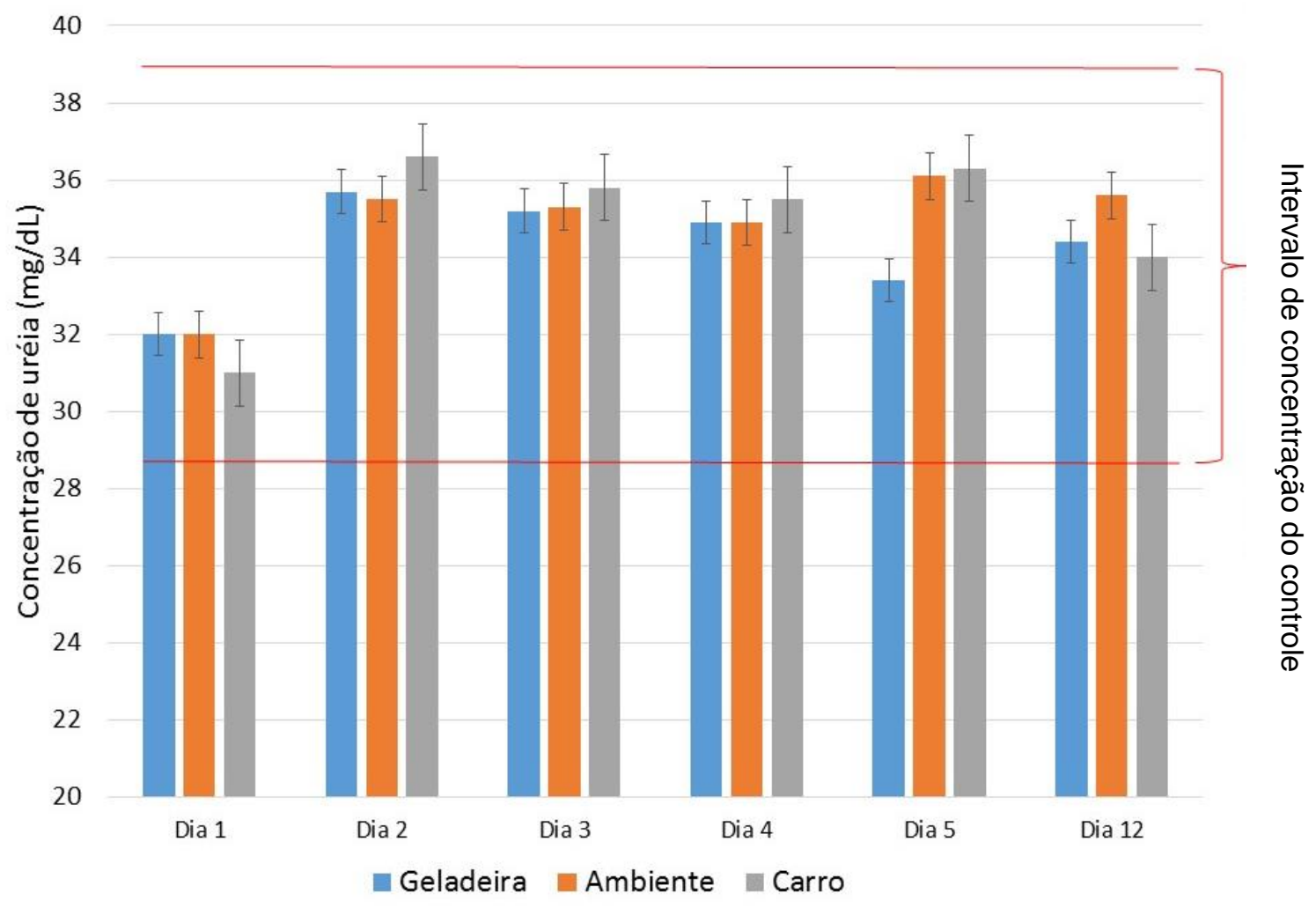

Fonte: os autores.

Em relação aos dados obtidos para creatinina (Figura 5), pode-se notar que nos 4 primeiros dias de análise, todas as alíquotas mantiveram concentrações dentro dos valores estabelecidos nas instruções de uso, independente da temperatura de armazenamento. Já para a alíquota armazenada sob refrigeração no $5^{\circ}$ dia, assim como as alíquotas estocadas por 12 dias, para as três temperaturas de armazenamento avaliadas, foram mensurados valores abaixo da faixa estabelecida para o controle estudado. Isto indica que para tal analito, o tempo de armazenagem apresenta influência na estabilidade, assim como a temperatura de refrigeração a que são submetidas as alíquotas, visto que a $4 \stackrel{\circ}{\circ}$, a concentração de creatinina foi inferior que as demais temperaturas em todos os períodos estudados. Mesmo comportamento foi reportado em estudos prévios, onde Fernandes et al. (2001) observaram que a creatinina plasmática de cães apresentou diminuição significativa da concentração a $6 \mathrm{~h}$ e $12 \mathrm{~h}$ após a primeira análise, quando submetidas à temperatura ambiente e a refrigeração $(2$ a $8 \stackrel{\circ}{\circ})$, respectivamente. Na dosagem de creatinina em amostras de sangue de cães, Thoresen et al. (1992) relataram instabilidade em soro e plasma heparinizado quando armazenado com o coágulo à $4 \stackrel{\circ}{\mathrm{C}}$ e $20^{\circ} \mathrm{C}$. 
Figura 5 - Valores obtidos para o analito creatinina após o armazenamento em diferentes temperaturas

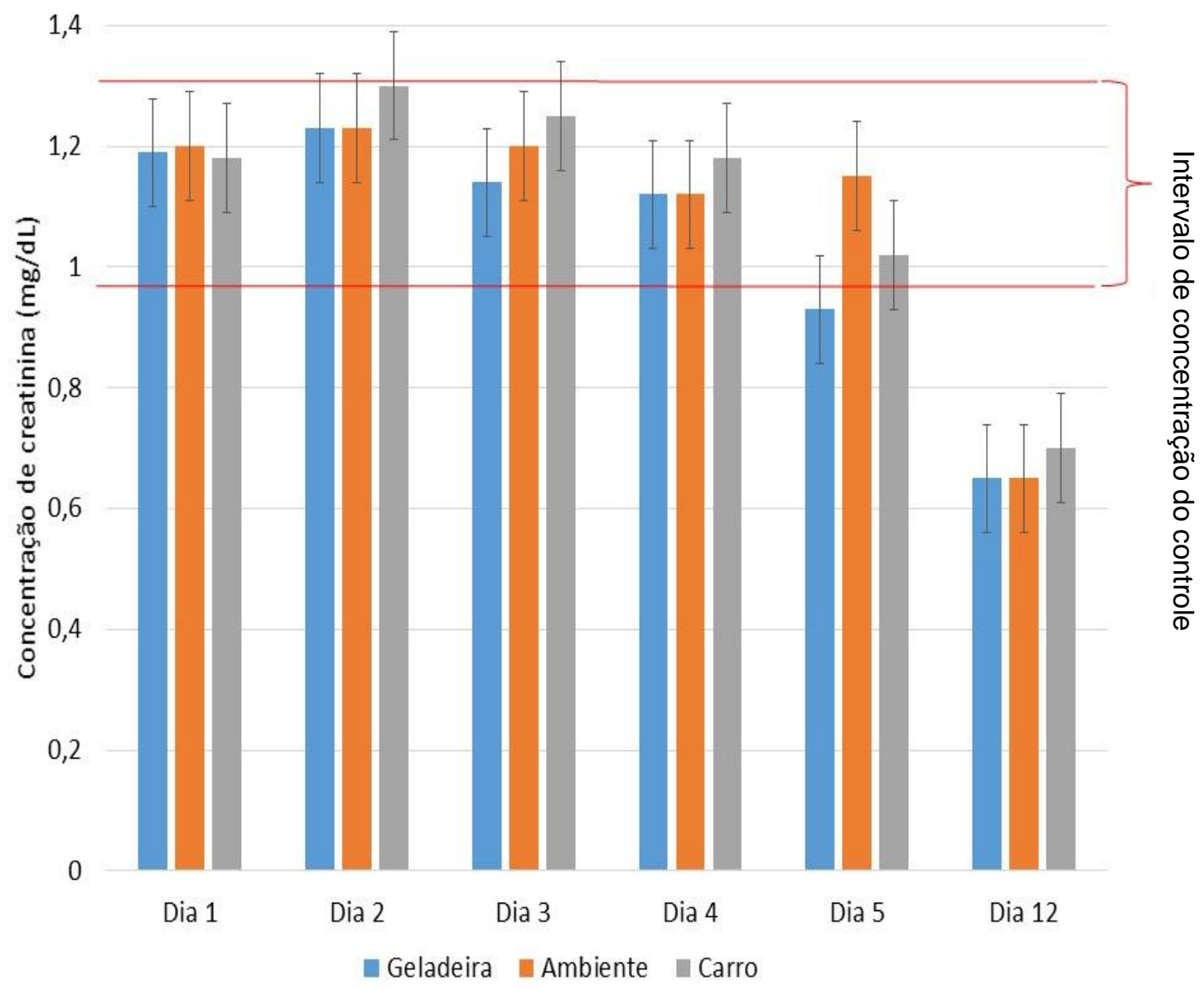

Fonte: os autores.

Em relação as enzimas transaminase (TGO e TGP), sabe-se que estas catalisam a transferência de um grupo amino de um aminoácido para um $\alpha$ cetoácido. No caso da TGO, o grupo amino do ácido aspártico é transferido para o ácido a-cetoglutárico, formando o ácido glutâmico, enquanto na TGP, o grupo amino da alanina é transferido para um ácido a-cetoglutárico, formando ácido glutâmico e ácido pirúvico.

Para o analito TGO (ou AST) (Figura 6), as alíquotas avaliadas apresentaram-se com concentrações dentro da faixa estabelecida para o controle, para todas as temperaturas avaliadas e nos diferentes tempos de armazenamento, indicando assim a estabilidade desse analito no produto avaliado. Já para o analito TGP (ou ALT) (Figura 7), com exceção da alíquota armazenada em altas temperaturas no carro, no 5o dia, todas as alíquotas avaliadas (em diferentes períodos de armazenagem, sob as três condições de temperatura) apresentaram concentrações dentro dos valores considerados para o controle testado. Como já discutido anteriormente, a existência de uma medida que não apresenta nenhuma tendência de diminuição ou aumento com o tempo, indica possivelmente a presença de erro sistemático (bias). 
Divya e Jayavardhanan (2010) observaram que a concentração de TGO para amostra de soro de caprinos diminui após 5 dias de armazenamento a temperatura ambiente enquanto aumenta após 14 dias de armazenamento sob refrigeração a $4 \stackrel{\circ}{\circ} \mathrm{C}$, assim como a concentração de TGP aumenta após 11 dias de armazenamento sob refrigeração. Juul (1967) reportou o aumento da concentração de TGO e TGP a partir de 1 dia da coleta de amostras de soro humano quando estas são mantidas a temperatura ambiente. Já de acordo com Nwosu et al. (2009), amostras refrigeradas de soro e plasma humanos apresentaram concentrações de TGO e TGP estáveis em até 30 horas se refrigeradas a $4{ }^{\circ} \mathrm{C}$ ou em até 8 horas a temperatura ambiente. Divya e Jayavardhanan (2011) avaliaram amostras de soro de búfalos e reportaram que a concentração de TGP é estável sob refrigeração a $4{ }^{\circ} \mathrm{C}$ por um período de 14 dias, mas instável a temperatura ambiente, apresentando diminuição contínua da concentração, enquanto TGP apresentou concentração estável por 11 dias sob refrigeração a $4 \stackrel{\circ}{ } \mathrm{C}$ e por 8 dias em temperatura ambiente.

Figura 6 - Valores obtidos para o analito Transaminase Glutâmico Oxalacética (TGO) após o armazenamento em diferentes temperaturas

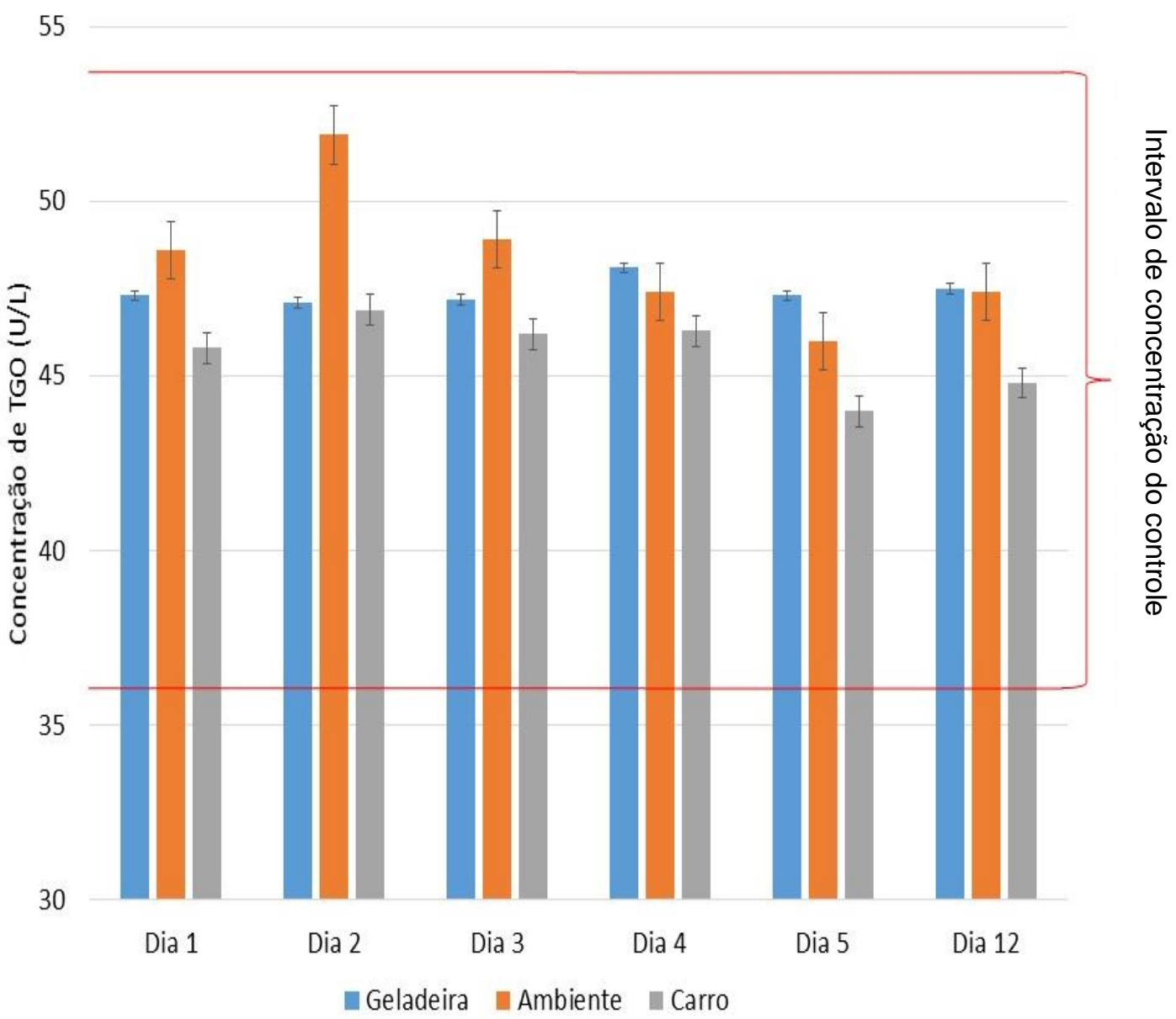

Fonte: os autores. 
Figura 7 - Valores obtidos para o analito Transaminase Glutâmico-Pirúvica (TGP) após o armazenamento em diferentes temperaturas

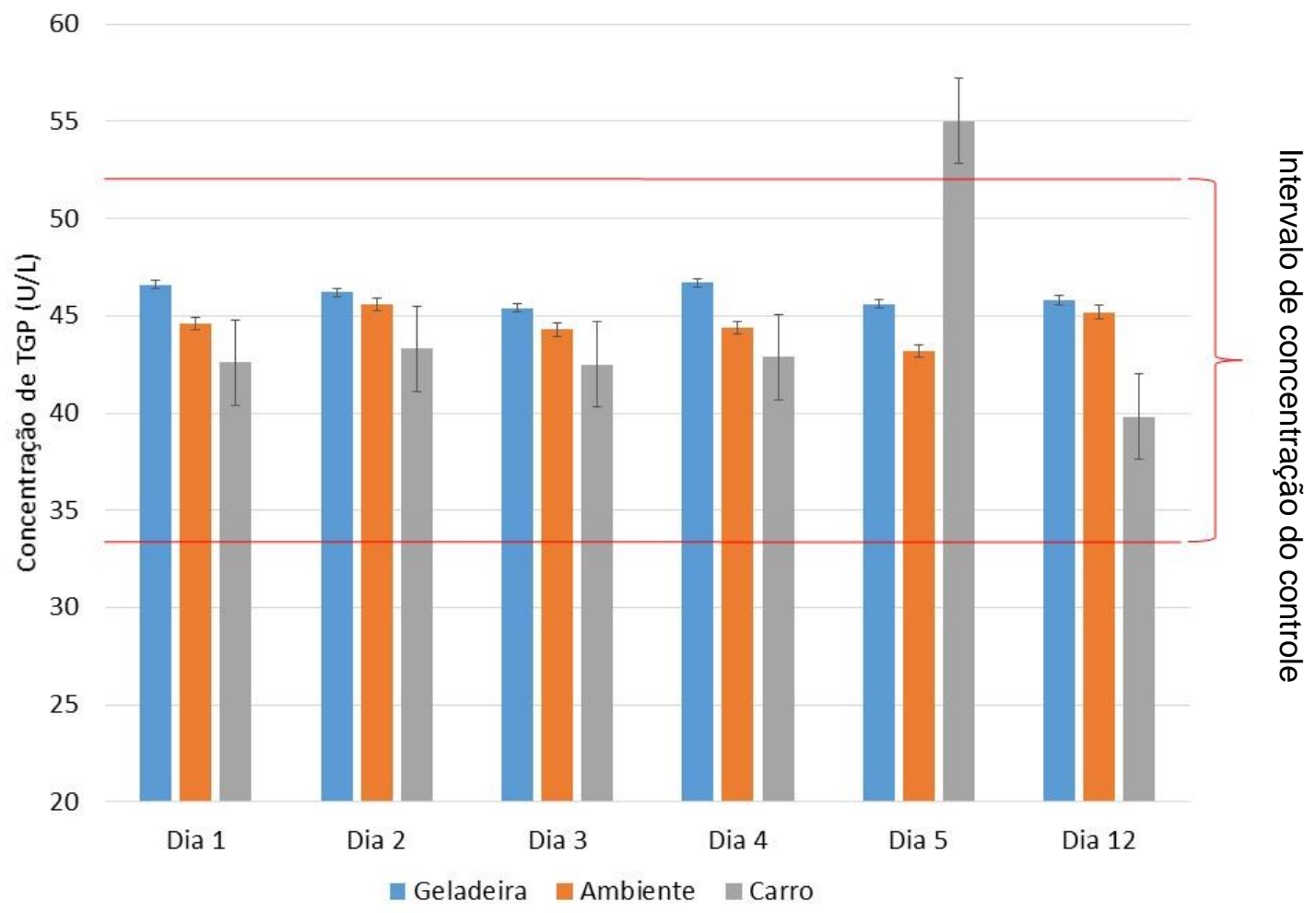

Fonte: os autores.

De acordo com Lange et al. (2018), discrepâncias de valores que não se explicam por uma linha de tendência condizente com uma eventual degradação da amostra ou evaporação do solvente, podem ser justificadas por erro sistemático da análise/preparação dos reagentes. Nesse mesmo contexto, Hollands e Logan (1966) afirmam que mesmo que os reagentes tenham sido devidamente preparados, se as instruções de uso não forem adequadas e se as precauções com demais fatores (controle de temperatura e $\mathrm{pH}$, efeitos de materiais interferentes, limpeza de vidraria, etc.) não são rigorosamente efetuadas, um erro considerável pode ser introduzido por um operador mesmo que ele tenha seguido todas as informações fornecidas pelo fabricante.

Observa-se que os dados obtidos neste estudo foram apresentados comparando-se a dados obtidos principalmente com amostras de soro e plasma humanos e de animais. A literatura é bastante escassa em relação a estudos de estabilidade de padrões de referência, calibradores ou reagente para análises de diagnóstico in vitro, onde dos poucos estudos encontrados, praticamente todos tratam da estabilidade em relação ao tempo de armazenamento, em temperaturas consideradas ideais, como as descritas pelos fabricantes.

Prakash et al. (2017), considerando o alto custo dos calibradores, e o fato de que os analitos são estáveis em soro por muito tempo, avaliou a estabilidade dos calibradores em tempos superiores aos indicados pelos fabricantes, que de forma geral indicam o uso dentro de $24 \mathrm{~h}$ após a preparação das soluções. Os testes foram realizados para os analitos glicose, colesterol total, proteína total, 
ferro e lactato desidrogenase a uma temperatura de armazenamento de $-20{ }^{\circ} \mathrm{C}$. Foi observado que o calibrador foi estável por tempo superior a 8 semanas para glicose, 7 semanas para colesterol total, 10 semanas para proteína, 28 semanas para ferro e 17 semanas para lactase desidrogenase, tempos muito superiores ao indicado pelos fabricantes.

O único estudo sobre a estabilidade em relação a temperatura de armazenagem, utilizando-se kits de biosensores que contem juntamente 0 padrão de calibração, foi apresentado por Snyder (2011), que mostra que em condições de armazenamento de aproximadamente $20^{\circ} \mathrm{C}$ acima da temperatura indicada pelo fabricante, ocorre uma diminuição nas concentrações dos analitos em cerca de $40 \%$. Já para a armazenagem acima $10{ }^{\circ} \mathrm{C}$ da temperatura referência, a diminuição da concentração dos analitos foi de aproximadamente $20 \%$.

\section{CONCLUSÃO}

A partir dos resultados obtidos para as concentrações mensuradas dos analitos estudados no controle, pode-se concluir que tanto o tempo quanto a temperatura em que as alíquotas são armazenadas não ocasionam alterações significativas nesse produto (apesar de valores divergentes possivelmente devido a erro sistemático), apresentando valores dentro das faixas estimadas para o Qualitrol 1H. Assim, faz-se necessários estudos complementares relativos a outros controles, a fim de se identificar possíveis erros sistemáticos na preparação das alíquotas, ou de se identificar problemas em relação ao produto.

De qualquer forma, considerando-se a seriedade e importância das análises para as quais se utilizam tais controles, recomenda-se que os laboratórios de análises clínicas desenvolvam rotinas rígidas para verificação de precisão e exatidão dos resultados, além do uso de controles, utilizados de forma rotineira. Também, observa-se a possibilidade concreta de instaurar ações de controle de qualidade no serviço de bioquímica clínica, como manutenção dos equipamentos bioquímicos e pipetas, treinamento de recursos humanos e criação de cultura de qualidade entre os envolvidos no serviço Neste âmbito, ainda que se trabalhe com fatores teóricos dos fabricantes, cabe ao laboratório padronizar, validar e documentar todo o processo dos reagentes, objetivando evitar o erro total e garantir valores precisos do ponto de vista clínico.

\section{REFERÊNCIAS}

BADRICK, T. The quality control system. Clinical Biochemistry, v. 29, n. Suppl. 1, p. 67-70, 2008.

BROOKS, Z. C. Performance-driven quality control. Washington, DC: AACC Press, 2001.

DIVYA, P.; JAYAVARDHANAN, K. Effect of temperature and storage time on hepatobiliary enzyme activities in goat serum. Veterinary World, v. 3, n. 6, p. 277, 2010. 
DIVYA, P.; JAYAVARDHANAN, K. Comparative study and storage stability of serum hepatobliliary enzyme activities in Murrah buffaloes. Buffalo Bulletin, v. 30, n. 3, p. 195-201, 2011.

FERNANDES, S. T.; TEIXEIRA, M. N.; SANTOS, E. S. Influência da temperatura e do tempo de armazenamento nas dosagens bioquímicas de uréia e creatinina em soro ou plasma caninos. Arquivo Brasileiro de Medicina Veterinária e Zootecnia, v. 53, n. 6, p. 648-651, 2001.

HEINS, M.; HEIL, W.; WITHOLD, W. Storage of Serum or Whole Blood Samples? Effects of Time and Temperature on 22 Serum Analytes. Clinical Chemistry and Laboratory Medicine, v. 33, n. 4, p. 231, 1995.

HOLLANDS, M.; LOGAN, J. An examination of commercial kits for the determination of glutamic oxaloacetic transaminase (GOT) and glutamic pyruvic transaminase (GPT) in serum. Canadian Medical Association Journal, v. 95, n. 7, p. 303-306, 1966.

JUUL, P. Stability of plasma enzymes during storage. Clinical Chemistry, v. 13, n. 5, p. 416-422, 1967.

KONIECZKA, P.; NAMIESNIK, J. Quality assurance and quality control in the analytical chemistry laboratory: a practical approach. Taylor \& Francis, 2009.

LANGE, L. A. Avaliação da qualidade e da estabilidade de amostras de soro humano para análise e armazenamento em biorrepositório. Revista Brasileira de Análises Clínicas, v. 50, n. 1, p. 50-56, 2018.

LINDNER, A. Einflub von lagerungsdauer, temperatur und probenausgangsmaterial auf klinish-chemische blutearrablen. Journal of the American Veterinary Medical Association, v. 38, p. 433-440, 1991.

LOPES, H. J. D. J. Garantia e controle da qualidade no laboratório clínico. Gold Analisa Diagnóstica, 2013.

NWOSU, O.; ALOH, G.; IHEDIOHA, J. Changes in alt, ast and alp values of plasma and serum samples stored at refrigerator $\left(4^{\circ} \mathrm{C}\right)$ and room temperature $\left(32^{\circ} \mathrm{C}\right)$ for up to five days. Bio-Research, v. 7, n. 2, p. 496-501, 2009.

PRAKASH, S. N.; DEVANATH, A.; AHLAD. Calibrator: How Long is it Stable? . International Journal of Clinical Biochemistry and Research, v. 4, n. 4, p. 348-353, 2017.

RICÓS, C. et al. Commutability and traceability: their repercussions on analytical bias and inaccuracy. Clinica Chimica Acta, v. 280, n. 1-2, p. 135-145, 1999.

ROSATO, P. N. Estabilidade de constituintes bioquímicos frente a diferentes temperaturas e períodos de estocagem, em amostras de soro de 
cães hígidos. 2007. 57f. Dissertação (Mestrado em Medicina Veterinária) Universidade Estadual Paulista, Jaboticabal, 2007.

SNYDER, S. L. Modeling the Thermal Stability of in vitro Diagnostic Bioassays. 2011. 69f. Tese (Mestrado em Ciências Aplicadas) - Queen's University, Kingston, Ontario, Canada, 2011.

TAMBWEKAR, S. Handbook of quality assurance in laboratory medicine. New Delhi: Ed. BI Publications PVT, 2009.

THORESEN, S. I. et al. Effects of storage time on chemistry results from canine whole blood, heparinized whole blood, serum and heparinized plasma. Veterinary Clinical Pathology, v. 21, n. 3, p. 88-94, 1992.

THORESEN, S. et al. Effects of storage time and freezing temperature on clinical chemical parameters from canine serum and heparinized plasma. Veterinary Clinical Pathology, v. 24, n. 4, p. 129-133, 1995.

WESTGARD, J. O.; KLEE, G. G. Quality Management. In: BURTIS, C. A. A. E. R.; BRUNS, D. E. Textbook of clinical chemistry and molecular diagnostics. USA: Elsevier Saunders, 2006. 